NASA TECHNICAL MEMORANDUM $104160 p-31$

\title{
EFFECTS OF ELEVATED TEMPERATURE ON THE VISCOPLASTIC MODELING OF GRAPHITE/POLYMERIC COMPOSITES
}



Thomas S. Gates

\section{OCTOBER 1991}

\section{N/Sก \\ National Aeronautics and Space Administration}

Langley Research Center Hampton, Virginia 23665-5225 


\section{Abstract}

In order to support the devclopment of new materials required for the design of next generation commercial supcrsonic transports, a research program is underway at NASA to assess the long term durability of advanced polymer matrix composites (PMC's). In support of this program, recent work has provided test methods and an elastic/viscoplastic constitutive model which accounted for some aspects of rale-dependent tension and compression loading behavior of IM7/5260 (graphite/bismaleimide) and IM7/8320 (graphite/thermoplastic) materials throughout a range of useful temperatures. The research effort detailed in this paper is an extension of that work and had two main objectives. The first objective was to explore the effects of elevated temperature $\left(23^{\circ} \mathrm{C}\right.$ to $\left.200^{\circ} \mathrm{C}\right)$ on the constitutive model's material parameters. 'To achieve this goal, test data on the observed nonlinear, stress/strain behavior of IM7/5260 and IM7/8320 composites under tension and compression loading was collected and correlated against temperature. These tests, conducted under isothermal conditions using variable strain rates, included such phenomena as stress relaxation and short term creep. From this data, trends in the parameters at elevated temperatures were developed, differences between the two material systems were outlined, and the significance of the parameters in terms of ductility and rate dependent behavior was established. The second major goal was the verification of the model by comparison of analytical predictions and test results for off-axis and angle-ply laminates. Correlation between test and predicted behavior was performed for specimens of both material systems over a range of temperatures. Results indicated that the model provided reasonable predictions of material behavior in load or strain controlled tests. Periods of loading, unloading, stress relaxation and creep were accounted for. These types of studies should be useful for making comparisons on the effect of temperature between specific laminate types and material systems. 


\section{Nomenclature}

$\Lambda$ - quasistatic elastic/plastic material parameter

$A^{\prime}$ - laminate stiffncss matrix

$a_{66}-$ potential function material parameter

E - elastic Young's modulus

f - potential function

G - clastic shear modulus

H - overstress

K - elastic/viscoplastic material parameter

$\mathrm{m}$ - elastic/viscoplastic material parameter

n - quasistatic clastic/plastic material parameter

Q - stiffness matrix

$S$ - compliance matrix

$T_{g}$ - glass transition temperature

$T_{\epsilon}$ - strain transformation matrix

$T_{\sigma}$ - stress transformation matrix

$c$ - strain

$\epsilon^{\circ}$ - in-plane mid surface strain

$\dot{c}$ - strain rate

$\bar{c}$ - effective strain

$\overline{\dot{c}}$ - effective strain rate

$\Phi$ - overstress function

$\gamma$ - viscosity constant

$\lambda$ - proportionality constant

$\nu$ - Poisson's ratio

$\sigma$ - stress

$\dot{\sigma}$ - stress rate

$\bar{\sigma}$ - effective stress

$\bar{\sigma}$ - effective stress rate

$\sigma^{\star}-$ quasistatic stress

$\sigma^{\star}$ - effective quasistatic stress

$\Psi$ - function defined in equation 13

Subscripts

$\mathrm{i}, \mathrm{j}=1-3$, lamina material principal directions

Superscripts

c - elastic 

in - inelastic
p - plastic
$q p$ - quasistatic plastic
$\mathrm{T}$ - matrix transpose
vp - viscoplastic 


\section{Introduction}

The next generation high speed civilian transport is expected to be a supersonic aircraft capable of Mach 2+ cruise while carrying over 200 passengers. The high structural loads and elevated temperatures implicit in supersonic lansport operations, coupled with the requirements of long term durability, require that accurale analytical models be developed to ensure integrity of the vehicke over it's design lifetime. The use of polymer matrix composite (PMC) materials in both primary and sccondary structure will require a broad understanding of material constitutive relationships. One area of particular interest is the nonlinear, time-dependent constitutive relationships which must be developed to model a P.IC's stress/strain behavior over a range of uschul t,emperatures.

Time-dependent constitutive relations presented in viscoclastic and viscoplastic theories provide a means of modeling rale dependent phenomena such as crecp, recovery, relaxation and strain rate dependency. Several models which were developed for PMC's are reviewed by the author in reference [1]. In that review, the elastic/viscoplastic constitutive model developed by Gates and Sun [2] was used to predict the response of an orthotropic material loaded under simple, in-planc tension. Material parameters and related functions needed by the constitutive model were found by performing uniaxial tension tests on off-axis laminates. To provide a means for predicling the nonlincar, rate dependent stress/strain behavior of laminated PMC's at elevated temperature, under tension or compression loads, the author has developed a modified form of this clastic/viscoplastic constitutive model. Both the orthotropic plate and laminaled plate forms of this model have been presented by the author in reference [3]. Experimental procedures and methods required to generate material parameters for this model are given in [4].

The approach taken in [3] and [4] was to allow the temperature dependency of the material to be accounted for by the variation in material parameters. For this report, data from [3], [4] and subsequent test data generated at N $\triangle$ S $\Lambda$ Langley Research Center on the observed isothermal, rate-dependent behavior of IM7/5260 ${ }^{\prime}$ and IM7/8320 ${ }^{1}$ composites under tension and compression loading are presented and trends in the matcrial parameters with respect to temperature are shown. The physical significance of these trends in regards to viscoplastic behavior are discussed.

In addition, in this report, predicted behavior from the orthotropic plate and laminated plate form of the Gates/Sun model is compared to test data for off-axis and $[ \pm 45]_{2}$, laminates under uniaxial loads. 'The offects of temperature on the predicted stress/strain response of

\footnotetext{
'The use of trade names in this paper does not constitute endorsement, either expressed or implied, by the National Acronautics and Space Administration.
} 
these laminates and the temperature effects on the predicted creep and stress relaxation behavior of off-axis layups are also presented.

\section{Constitutive Model Description}

In order to understand where the matcrial parameters required by the Gates/Sun model originate, a brief outline of the constitutive model is required. The model is considered an macromechanical, elastic/viscoplastic constitutive model which is phenomenological in form. The ability to account for temperature effects is liandled through the variation of material properties with temperature. The model can be applied to tension or compression loading. Ilowever, for easc of prescntation, the expressions given below assume a positive (tension) loading.

Assuming in-plane loading and plane stress conditions, the strain rate is assumed to be composed of elastic and viscoplastic components.

$$
\{\dot{\epsilon}\}=\left\{\dot{\epsilon}^{e}\right\}+\left\{\dot{c}^{v p}\right\}
$$

The individual constitutive relations are given as

$$
\left\{\dot{\epsilon}^{e}\right\}=[S]^{e}\{\dot{\sigma}\} \quad \text { elastic }
$$

and

$$
\left\{\dot{\epsilon}^{2 p}\right\}=[S]^{v p}\{\dot{\sigma}\} \quad \text { viscoplastic }
$$

The elastic compliance term is linear and independent of stress level. Using a formulation such as found in T'sai and IIahn [5], the clastic compliance matrix is written as

$$
[S]^{e}=\left[\begin{array}{ccc}
\frac{1}{E_{1}} & \frac{-\nu_{12}}{E_{1}} & 0 \\
\frac{-\nu_{12}}{E_{1}} & \frac{1}{E_{2}} & 0 \\
0 & 0 & \frac{1}{G_{12}}
\end{array}\right]
$$

where the terms $E_{1}, E_{2}, C_{12}$ and $\nu_{12}$ are constants referenced to the material principal axis.

The viscoplastic compliance matrix can be decomposed further into time dependent plastic and inclastic components

$$
[S]^{v p}=[S]^{p}+[S]^{i n}
$$

The viscoplastic compliance matrix is a nonlincar function of stress and is partially derived using the "overstress" concept. The concept of overstress and its relationship to viscoplastic strain in isotropic melallic materials has been attributed to Malvern[6] and his work 
on high strain rate conditions during wave propagation. Additional references to overstress and its use in constructing viscoplastic models can be found in the work of Eisenberg and Yen[7,8] and Krempl and IIong[9].

In general, Malvern stated that the overstress is the excess of the rate dependent stress over the stress at the same strain in a quasistatic test. For the PMC, overstress $(H)$ is defined as

$$
H \equiv\left(\bar{\sigma}-\bar{\sigma}^{\star}\right)
$$

where $(\bar{\sigma})$ is the rate dependent effective stress and $\left(\sigma^{\star}\right)$ is the rate independent or quasistatic effective stress.

The effective stress is found by using the formulation of Sun and Chen [10]. In this approach, a potential function $\int\left(\sigma_{i j}\right)$ which accounts for material anisotropy, was formed by assuming clastic behavior along the fiber direction and plane stress conditions.

$$
2 \int\left(\sigma_{i j}^{\star}\right)=\sigma_{22}^{2 *}+2 a_{66} \sigma_{12}^{2 *}
$$

Where $\sigma_{22}^{\star}$ and $\sigma_{12}^{\star}$ are the inplane transverse and shear quasistatic stress components respectively. The single material constant is given by the $a_{66} \mathrm{term}$ and can be found from axial tests of off-axis specimens.

Using the potential function above, the effective quasistatic stress is defined by

$$
\bar{\sigma}^{\star} \equiv \sqrt{3 f\left(\sigma_{i j}^{\star}\right)}
$$

and similarly, the rate dependent effective stress is

$$
\bar{\sigma} \equiv \sqrt{3 \int\left(\sigma_{i j}\right)}
$$

As given by Sun and Chen [10], the quasistatic elastic/plastic constitutive relations are

$$
\begin{gathered}
\left\{d \epsilon^{e}\right\}=[S]^{e}\left\{d \sigma^{\star}\right\} \quad \text { clastic } \\
\left\{d \epsilon^{q p}\right\}=[S]^{q p}\left\{d \sigma^{\star}\right\} \quad \text { quasistatic plastic }
\end{gathered}
$$

The quasistatic plastic compliance matrix was written as

$$
[S]^{q p}=\Psi\left[\begin{array}{ccc}
0 & 0 & 0 \\
0 & \sigma_{22}^{2} & 0 \\
0 & 0 & 4 a_{66}^{2} \sigma_{12}^{2}
\end{array}\right]
$$

where the term $\Psi$ can be written

$$
\Psi=\frac{9}{4 \bar{\sigma}^{2}} \frac{d \bar{c}^{q p}}{d \bar{\sigma}}=\frac{9}{4} n A \bar{\sigma}^{(n-3)}
$$


and all of the stress terms are quasistatic $\left(\sigma^{\star}\right)$. The effective quasistatic plastic strain $\left(\tilde{\epsilon}^{q p}\right)$ is derived using a form of the associated flow law and the expression

$$
d \epsilon^{q p}=\frac{2}{3} \bar{\sigma}^{\star} d \lambda
$$

where $d \lambda$ is the proportionality constant.

$\Lambda$ power law was assumed for the effective stress, effective plastic strain relation. Functionally, this can be writlen as

$$
\bar{\epsilon}^{q p}=A\left(\bar{\sigma}^{\star}\right)^{n}
$$

where $A$ and $n$ are material parameters found from fitting the power law to the effective stress, effective plastic strain data.

For the plastic strain rate term, the compliance matrix is

$$
[S]^{p}=\gamma \frac{3}{2 \bar{\sigma}}\langle\Phi(I I)\rangle\left[\begin{array}{ccc}
0 & 0 & 0 \\
0 & \frac{\sigma_{22}}{\dot{\sigma}_{22}} & 0 \\
0 & 0 & \frac{2 a_{66} \sigma_{12}}{\dot{\sigma}_{12}}
\end{array}\right]
$$

where $\Phi(I I)$ is the overstress function and $\gamma$ is a constant with a value of unity and units of $\left(\right.$ sec. $\left.^{-1}\right)$. The Macaulay $(\langle\rangle)$ brackets imply a conditional statement which can be written in a general sense as

$$
\langle\Phi(I I)\rangle= \begin{cases}\Phi(I I) & \text { if } I>0 \\ 0 & \text { if } I \leq 0\end{cases}
$$

In terms of a functional relationship, a power law expression was used to model test data giving the effective plastic strain rate as

$$
\bar{\iota}^{p}=\gamma\langle\Phi(I I)\rangle=\gamma\left[\frac{\langle I I\rangle}{K}\right]^{(1 / m)}
$$

where $K$ and $m$ are matcrial parameters found from fitting a power law to the overstress, effective plastic strain rate data.

The inelastic rate term is found from differentiating the quasistatic expression and expanding.

$$
[S]^{i n}=\frac{\bar{\sigma}(n-3)}{3 \bar{\sigma}} \Psi\left[\begin{array}{ccc}
0 & 0 & 0 \\
0 & \frac{\sigma_{22}^{3}}{\dot{\sigma}_{22}} & 0 \\
0 & 0 & \frac{4 a_{66}^{2} \sigma_{12}^{3}}{\dot{\sigma}_{12}}
\end{array}\right]+\Psi\left[\begin{array}{ccc}
0 & 0 & 0 \\
0 & \sigma_{22}^{2} & 0 \\
0 & 0 & 4 a_{66}^{2} \sigma_{12}^{2}
\end{array}\right]
$$


where $\Psi$ is defined above and the effective stress rate is

$$
\overline{\bar{\sigma}}=\frac{3}{2 \bar{\sigma}}\left(\sigma_{22} \dot{\sigma}_{22}+2 a_{66} \sigma_{12} \dot{\sigma}_{12}\right)
$$

Using these equations, the multiaxial constitutive relation can be written in a more compact form as;

$$
\left\{\dot{c}^{v p}\right\}=[S]^{p}\{\dot{\sigma}\}+\frac{1}{2}\left(\gamma \frac{\dot{\sigma}(n-3)}{3 \sigma}[S]^{i n^{\prime}}\{\dot{\sigma}\}+[S]^{q p}\{\dot{\sigma}\}\right)
$$

The coefficient of $\frac{1}{2}$ was used to give a good correspondence to test data over the range of test temperatures.

This model can be used to describe the nonlinear, rate dependent behavior in a laminated composite. For such a laminated composite, typical notation from lamination theory is used so that $Q_{i j}$ is the stiffness matrix and $S_{i j}$ is the corresponding compliance matrix. It is noted that the transformed stiffness and compliance matrices are given in the usual manner by

$$
\begin{gathered}
{[\bar{Q}]=\left[T_{\sigma}^{\prime}\right]^{-1}[Q]\left[T_{\epsilon}^{\prime}\right]=\left[T_{\epsilon}\right]^{T}[Q]\left[T_{\epsilon}\right]} \\
{[\bar{S}]=\left[T_{\sigma}\right]^{T}[S]\left[T_{\sigma}\right]}
\end{gathered}
$$

where $\left[T_{\sigma}\right]$ and $\left[T_{c}\right]$ are the common stress and strain tensor transformation matrices. This gives the constitutive equations for the quasistalic elastic/plastic case to be;

$$
\begin{aligned}
& \{d \sigma\}_{k}=[\bar{Q}]_{k}^{e}\left\{d c^{c}\right\}_{k} \quad \text { elastic } \\
& \{d \sigma\}_{k}=[\bar{Q}]_{k}^{q p}\left\{d \epsilon^{q p}\right\}_{k} \quad \text { plastic }
\end{aligned}
$$

The subscript $k$ refers to the individual or k'th layer in the laminate. If a form is used such that;

$$
[\bar{Q}]^{e q p}=[\bar{Q}]^{\epsilon}+[\bar{Q}]^{q p}
$$

then, for in-plane axial loading of a balanced symmetric laminate, the combined expressions may be written for the quasistatic clastic/plastic laminated plate as;

$$
\{d N\}=\left[A^{\prime}\right]^{e q p}\left\{d \epsilon^{\circ}\right\}
$$

Where, $N$ are the plate resultant forces, $\epsilon^{\circ}$ are the laminate in-plane strains of the midsurface, and $A^{\prime}$ is the laminate stiffness matrix. 
Similarly, for the elastic/viscoplastic case, it can be written;

$$
[\bar{Q}]^{e v p}=[\bar{Q}]^{e}+[\bar{Q}]^{u p}
$$

then, the combined expressions may be written for the elastic/viscoplastic case as;

$$
\left\{\frac{d N}{d t}\right\}=\left[A^{\prime}\right]^{e v p}\left\{\frac{d \epsilon^{\circ}}{d t}\right\}
$$

The model is formulated to predict nonlinear, rate dependent behavior including such phenomena as creep, stress relaxation and strain rate dependency. Creep recovery after unloading is not accounterl for in the model. For an orthotropic plate, the uniaxial elastic/viscoplastic constitutive model was solved numerically using the fourth order RungeKutta [11] technique with a modified Newton technique [11] to find the roots of the quasistatic equation. For a laminated plate, predictions werc made using a time stepping incremental scheme to solve the system of differential equations for both the quasistatic and ratedependent solutions. The equations were solved numerically by using the previous stresses to update the compliance matrices and directly solving for the unknowns using lower/upper decomposition with back substitution.

\section{Materials Testing}

All of the tests needed to generate material constants and parameters, or provide verification of the analytical model, were conducted under isothermal conditions using either monotonic tension or compression loads [4]. The six temperatures selected for study were $23^{\circ}, 70^{\circ}, 125^{\circ}, 150^{\circ}, 175^{\circ}$ and $200^{\circ} \mathrm{C}$.

\section{Test Specimens and Material}

Rectangular test specimens similar to those described in ASTM specification D3039-76 [12], consisting of twelve plys and measuring $2.54 \mathrm{~cm}$. by $24.1 \mathrm{~cm}$., were cut from laminated panels fabricated at NASA. The same geometry was used for both the tension and compression specimens.

For the four clastic material constants, lests were run on $\left[0^{\circ}\right]_{12},\left[90^{\circ}\right]_{12}$ and $\left[ \pm 45^{\circ}\right]_{2 s}$ specimens in order to determine $E_{1}, \nu_{12}, E_{2}$ and $G_{12}$. Procedures similar to those outlined in $\Lambda$ STM specifications D3039-76 and D3518-76 [12] were used to generate the constants.

For the three elastic/plastic $\left(a_{66}, A, n\right)$ and two elastic/viscoplastic $(K, m)$ material parameters, off-axis tests on $15^{\circ}, 30^{\circ}$ and $40^{\circ}$ coupons were performed using the rectangular 
specimen geometry described above. The specimens had an aspect ratio of 9.5:1 measured between the specimen ends and $8: 1$ measured between the test machine grips.

Two polymer matrix composite material systems were investigated in this study. The first, an amorphous graphite/thermoplastic was composed of Hercules IM7 fiber and Amoco 8320 matrix. The second material under study was a graphite/bismaleimide composed of Ilercules IM7 fibers and Narmco 5260 matrix. Both material systems had glass transition temperatures $\left(T_{g}\right)$ listed by the manufacture to be approximately $220^{\circ} \mathrm{C}$.

\section{Material Constants}

Aside from the four elastic constants, five material parameters are required by the analytical model for any given temperature. These constants are: $a_{66}$ for the potential function, $A$ and $n$ for the quasistatic elastic/plastic relations, and $K$ and $m$ for the rate dependent clastic/viscoplastic relations. 'These parameters were all found using data from simple offaxis tension or compression tests.

As shown in reference [4], using a strain controlled test and an approach similar to that outlined by Yen [13], all the quasistatic and rate-dependent constants can be extracted from uniaxial tests of off-axis specimens with repeated holds built into the test to allow stress relaxation to occur. The effective quasistatic stress/strain curves from different off-axis tests can then be plotted together and collapsed into a single master curve by selecting the appropriate value of $a_{66} . \Lambda$ power law fit to this curve determines $A$ and $n$.

During stress relaxalion, the total strain rate is zero, therefore, the viscoplastic term can be equated to the stress rate divided by the clastic modulus. During relaxation, the overstress and the stress rate can be defined for any point in time. This allows the construction of an overstress $(H)$ versus effective viscoplastic strain rate function $(\Phi)$ graph. These master curves are fit with a power law expression which gives the parameters $K$ and $m$.

\section{Experimental Procedures and Equipment}

In order to use the same specimen type on both the tension and compression tests, an aluminum fixture was fabricated at NASA which allowed for the application of heat while also providing the lateral support needed to suppress column buckling during a compression test. This fixture is shown in figure 1 . The fixture contained four resistance heater rods which provided zone control of the temperature. Thermocouple probes were used for feedback to the control unit. Heat from the fixture was transferred to the test specimen through direct contact of fixture and specimen along the length of the fixture and across the width of the 
specimen. Heat loss was controlled by enveloping both specimen and fixture in a reflective foil-lined clam-shell fiberglass insulator.

The buckling constraint for the compression tests was achieved by connecting the two fixture halves along their lengtli. Because of the continuous support along the length of the specimen, only a small amount of lateral force was needed to suppress buckling.

Testing for material constants was performed with a servo-hydraulic test machine capable of running predetermined load or strain history profiles. Axial strain was measured on the off-axis tests by using extensometers. For the $\left[0^{\circ}\right]_{12}$ and $\left[ \pm 45^{\circ}\right]_{2 s}$ tests, which required both axial and transverse strain measurement, back-to-back, center mounted high temperature foil strain gages were used. Load, as measured by the load cell, was converted to stress using the average cross-sectional area of the specimen measured prior to testing. The extensometers were connected to the load frame DC controllers while an external unit was used to amplify and condition the strain gage signals.

Previous work by Nemethly $[14]$ and others has shown that an off-axis test performed with clamped end conditions will give rise to an unequal strain distribution along the length of the specimen. These unequal strains, which occur due to the extension-shear coupling behavior under axial loads, will vary according to fiber angle and specimen aspect ratio. Based upon this previous work, using the $8: 1$ aspect ratio and performing the strain measurements in the center of the specimen, the percent error in elastic strain varied from $10 \%$ for $15^{\circ}$ specimens, to $1.7 \%$ for $40^{\circ}$ specimens. The implications of clamped end conditions on the nonlinear, rate-dependent response of of $[$-axis specimens has yet to be determined. Additional work on quantifying this behavior should be performed.

All of the analog data from the load, strain and temperature measurements were acquired and stored by a PC based data acquisition system. Converted signals were stored and displayed in real time by using software to control the $A / D$ and $I / O$ processes.

\section{Results}

$\Lambda$ complete list of the experimentally determined material properties and constants for both material systems is provided in table 1 . The variation with temperature in measured elastic constants $E_{1}, E_{2}$ and $G_{12}$ are shown in figures $2 \mathrm{a}, 2 \mathrm{~b}, 2 \mathrm{c}$ respectively. The trend in the measured transverse and shear moduli is decreased stiffness with increased temperature. The longitudinal modulus appears relatively insensitive to temperature. In general, the IM7/5260 material had higher stiffuess in all material principal dircctions than the IM7/8320 over the range of temperatures investigated.

The material constant, $a_{66}$ which appears in the potential function was found to be inde- 
pendent of temperature over the range investigated. However, it was found to be dependent upon material system. In addition, $a_{66}$ for IM7/8320 was found to be slightly dependent on whether the material was in tension or compression. This apparent lack of load direction symmetry does not invalidate the model. Many failure criteria, such as given by Tsai and Hahn [5] use potential functions which have loading direction dependent material constants. In addition, it has been experimentally observed [15] that thermoplastic composites under cyclic loading exhibit some unsymmetrical behavior during the first few cycles and then exhibit symmetry during any remaining cyclic loading. Results show that $a_{66}$ for IM7/5260 is greater than $a_{66}$ for IM7/8320. In general, as $a_{66}$ decreases, $\sigma_{12}$ must increase to satisfy yield. Or, as $a_{66}$ increases $\sigma_{22}$ has less contribution to plasticity.

Quasistatic effective stress versus effective plastic strain master curves are shown in figures $3 a-3 b$. These curves were formed using a minimum of two off-axis specimens per curve. The off-axis angles used varied from $15^{\circ}$ to $40^{\circ}$. Examining these curves, it is apparent that the IM7/5260 material shows less tendency towards nonlinear elastic/plastic behavior than the IM7/8320 system. Assuming ductility is a measure of plastic strain for a given stress, both systems show a definite trend towards increased ductility as temperature increases.

To explore the variation of the elastic/plastic material parameters $A$ and $n$ with temperature, a parametric study was conducted. Examining the sensitivity of the $\bar{\sigma}^{\star}$ versus $\bar{\epsilon}^{p}$ master curves to variations in $A$ and $n$ revealed that for a given material and loading direction, the exponent $n$ can be set to an average value for all temperatures while allowing $A$ to vary with temperature. Using this average $n$, and requiring the same goodness of fit as found previously, the fit to the master curve data is calculated once again only allowing $A$ to vary. The resulting curves, shown in figure $3 c$, illustrate how the material parameters $A$ varies with temperature. In general, $A$ increases with temperature. As $A$ increases for a fixed value of $n$, the effective plastic strain will also increase implying an increase in ductility. Both systems show a marked increase in $A$ as the $T_{g}$ of the material is approached. Table 2 gives the calculated values of $A$ for a fixed $n$.

From the rate dependent master curves of $I$ versus $\Phi$ such as shown in figures $4 \mathrm{a}-4 \mathrm{~b}$, a comparison of the two material systems shows that at a given temperature, the IM7/8320 material shows a greater tendency towards higher $\Phi$ than IM7/5260 does for an equivalent overstress. Since $\Phi$ is directly proportional to plastic strain rate, this trend implies that the IM7/5260 is exhibiting less viscoplastic behavior than the IM $7 / 8320$ for a given temperature.

Varying the rate dependent material parameters $K$ and $m$ in an approach similar to that used in the quasistatic case, the effect of temperature on these parameters can be found. For a given material and loading direction, the exponent $m$ can be set to an average value and the fit to the master curve data is performed again. Requiring the same goodness of fit as found from the first curve fit, the master curve is calculated once again only allowing $K$ 
to vary with temperature. The resulting variation of $K$ with temperature is shown in figure 4c. When plotted on the same scale, as in figure 4c, the IM7/5260 material shows a larger variation in $K$ with temperature than the IM7/8320 material. In general, as $K$ decreases, the effective plastic strain rate increases. This implies an increase in viscoplastic behavior. Comparing the two material systems, IM7/8320 shows less variation in viscoplastic behavior with temperature while IM7/5260 shows an increase in this behavior as the temperature increases. The values of $K$ for a fixed $m$ are given in table 2 .

Comparing the uniaxial off-axis and laminate test results against the analytical model shows that the model does well in predicting several phenomenon including short term stress relaxation, short term creep, linear elastic unloading and variable strain rate loading. Typical comparisons between test and predictions are given in figures 5-9. The intent behind showing these figures is to establish confidence in the predictive capabilities of the model.

To check the orthotropic plate model, tests were run on $\left[25^{\circ}\right]_{12}$ off-axis specimens. It should be noted that the $25^{\circ}$ data was not used to construct the master curves and therefore correlation between tests and predictions can be used to help verify the model. Figure 5 shows the relationships between stress, strain and time for a $25^{\circ}$ off-axis tension specimen at $125^{\circ} \mathrm{C}$. In this case, the test was run under strain control and the resultant stress was measured. Periods of constant positive and negative strain rate and stress relaxation comprise the input strain history. The predicted stress/time and stress/strain behavior is plotted against the measured values in figures $5 \mathrm{a}$ and $5 \mathrm{~b}$. A good correlation between test and predicted values is evident.

The stress/strain histories for two different off-axis specimens are given in figures $6 \mathrm{a}-6 \mathrm{~b}$. Both test and predicted values are shown. Figure 6 a shows a $\left[25^{\circ}\right]_{12}$ off-axis tension specimen at $200^{\circ} \mathrm{C}$. Given the proximity of this temperature to the $T_{g}$, the predicted values correlate well with the test data.

Figure $6 \mathrm{~b}$ gives test and predicted values for a strain controlled, uniaxial compression test of a $\left[30^{\circ}\right]_{12}$ off-axis specimen at $175^{\circ} \mathrm{C}$. The results indicate a reasonable correlation, but as was typical with most of the compression results, the comparison between test and predicted values was not as good as the tension cases.

Prediction of creep behavior is a good verification of the model because the material constants used for the creep prediction were found from the stress relaxation procedures described previously. Short term creep behavior of a $\left[15^{\circ}\right]_{12}$ off-axis specimen at $23^{\circ} \mathrm{C}$ and a $\left[25^{\circ}\right]_{12}$ off-axis specimen at $150^{\circ} \mathrm{C}$ are shown in figures $7 \mathrm{a}$ and $7 \mathrm{~b}$ respectively. The applied stress history, resultant strain history and predicted strain history are given. The correlation between test and predicted strain is typical for short term creep tests performed on both material systems.

To verify the laminate analysis, constant strain rate tension tests were run on $\left[ \pm 45^{\circ}\right]_{2 s}$ 
specimens at elevated temperature. These tests included periods of stress relaxation. Figures 8 and 9 show test versus prediction for two specimens, IM $7 / 5260$ at $23^{\circ} \mathrm{C}$ and IM7/8320 at $70^{\circ} \mathrm{C}$ respectively. The prediction of the upper bound (rate-dependent) and lower bound (quasistatic) responses are compared with the test results. The quasistatic predictions should coincide with the points of minimum stress achieved during stress relaxation, while the rate dependent predictions should coincide with the maximum stresses achieved during loading. Both figures show reasonable agreement between test and prediction.

Although no load- or temperature-induced damage was detected on the off-axis test specimens, post-test examinations of the elevated temperature angle-ply laminates revealed repeated transverse cracks in the surface plys. Initial signs of this cracking became apparent during the $150^{\circ} \mathrm{C}$ tests and crack density increased as the temperature increased. The inclusion of damage is not accounted for in the constitutive model, therefore no comparisons betwen test and theory were available for temperatures at $150^{\circ} \mathrm{C}$ or greater. Additional lests on several matrix-dominated layups are being performed to quantify these effects.

Using the constitutive model as an analysis tool, and with a full range of material constants available for input, comparisons can be made on the effects of temperature on various aspects of elastic/viscoplastic behavior. For example, figure 10a shows the predicted effect of temperature on the relaxation of an off-axis, IM7/5260 tensile specimen at a peak stress level of $69 \mathrm{MPa}$. These curves show the relative change in stress during relaxation versus time for temperatures ranges of $23^{\circ}-200^{\circ} \mathrm{C}$. The effects of elevated temperature, particularly above $150^{\circ} \mathrm{C}$, are apparent.

In a similar manner, figure $10 \mathrm{~b}$ shows the predicted effects of temperature on the creep strain of an off-axis, IM7/5260 tensile specimen at a constant stress of $76 \mathrm{MPa}$. As in figure $10 \mathrm{a}$, the effects of elevated temperature, particularly above $150^{\circ} \mathrm{C}$, are significant.

Figure 11 shows the effects of elevated temperature on the predicted stress/strain behavior of an IM7/5260 $\left[ \pm 45^{\circ}\right]_{2}$, laminate under tension for a constant strain rate of $200 \frac{\mu \epsilon}{s e c}$. As expected, the curves show an increase in ductility and decrease in stiffness as temperature increases.

\section{Summary}

In previous reports, an clastic/viscoplastic constitutive model was developed to describe the observed nonlinear, rate-dependent behavior. Formulations for the general multiaxial case and the specific uniaxial case were found for quasistatic and rate-dependent loading. Test methods and experimental procedures were also developed to generate material parameters and constants. The two primary objectives of this study were to understand the effects 
of elevated temperature on the material constants required by the model and to verify the predictive capabilities of the laminate analysis.

To address the first objective, the material response over a range of temperatures from $23^{\circ} \mathrm{C}$ to $200^{\circ} \mathrm{C}$ was investigated experimentally for both IM7/8320 and IM7/5260 materials. Both tension and compression loading of ofl-axis and angle-ply laminates were investigated. Using the off-axis test data, two parameter power law expressions were formulated to characterize the master curves of the two material systems. By fixing the exponents in these cxpressions and allowing the other parameter to vary with temperature, the temperature effects on the material response were studied. It was found from these studies that the parameter $A$ in the quasistatic expressions gave an indication of ductility in the material. In general, as $A$ increased, ductility increased. In addition, it was found that the parameter $K$ in the viscous expressions gave an indication of rate dependency or viscoplastic behavior. In general, as $K$ decreased, rate depcndency increased.

In order to address the second objective, comparisons between off-axis and laminate test data and predicted values were made. Results indicated that the model provides reasonable predictions of the behavior of load or strain controlled tests. Periods of loading, unloading, stress relaxation and creep were accounted for.

Utilizing the predictive capability of the model, additional analytical studies were conducted to quantify the effects of temperature on such phenomena as stress relaxation, creep and ductility. Results from these studies should be useful for making comparisons on the effect of temperature between specific laminate types and material systems.

\section{References}

[1] T. S. Gates. Rate Dependent Constitutive Models for Fiber Reinforced Polymer Composites. NASA TM 102665, NASA Langley Research Center, May 1990.

[2] T.S. Gates and C.T. Sun. An Elastic/Viscoplastic Constitutive Model for Fiber Reinforced Thermoplastic Composites. AIAA Journal, 29, no.3:457-463, March 1991.

[3] T. S. Gates. Rate Dependent Stress-Strain Behavior of Advanced Polymer Matrix Composites. NASA TM 104070, NASA Iangley Research Center, April 1991.

[4] T.S. Gates. Experimental Characterization of Nonlinear, Rate Dependent Behavior in Advanced Polymer Matrix Composites. In Spring Conference on Experimental Mechanics, Society for Experimental Mechanics, Millwaukee, Wisconson, June 2-4 1991. 
[5] S. W. Tsai and H. T. IIahn. Introduction to Composite Materials. Technomic Publishing Co., Inc. 265 Post Road West, Westport, CT 06880, 1980.

[6] L.E. Malvern. The Propagation of Longitudinal Waves of Plastic Deformation in a Bar of Material Exhibiting a Strain-Rate Effect. ASME Journal of Applied Mechanics, $18: 203-208,1951$.

[7] M.A. Eisenberg and C.F. Yen. A Theory of Multi-Axial Anisotropic Viscoplasticity. ASME Journal of Applied Mechanics, 48:276-28, June 1981.

[8] M.A. Eisenberg and C.F. Yen. The Anisotropic Deformation of Yield Surfaces. In American Society of Mechanical Engineers, Winter Meeting, New Orleans, Louisiana, December 9-14 1984 .

[9] E. Krempl and B.7. Ilong. $\Lambda$ Simple Laminate Theory Using the Orthotropic Viscoplasticity Theory Based on Overstress. Part I: In-plane Stress-Strain Relationships for Metal Matrix Composites. Composites Science and Technology, 35:53-74, 1989.

[10] C.T. Sun and J.L. Chen. A Simple Flow Rule for Characterizing Nonlinear Behavior of Fiber Composites. Journal of Composite Materials, 23:1009-1020, October 1989.

[11] W.H. Press, B.P. Flannery, S.A. Teukolsky, and W.T. Vetterling. Numerical Recipes, The Art of Scientific Computing. Cambridge University Press, The Pitt Building, Trumpington Street, Cambridge CB2 1RP, U.K., 1986.

[12] ASTM, editor. 1990 Annual Book of ASTM Standards. Volume 15.03, American Society for Testing and Materials, 1990.

[13] C.F. Yen, K.F. Wang, and W.C. Isiao. An Experimental Study of the Uniaxial RateDependent Behavior of Type 304 Stainless Steel at Room Temperature. In Spring Conference on Experimental Mechanics, Society for Experimental Mechanics, New Orleans, Louisiana, June 8-13 1986.

[14] M.P. Nemeth, C.T. Herakovich, and D. Post. On the Off-Axis Tension Test for Unidirectional Composites. Composites Technology Review, 5(2):61-68, Summer 1983.

[15] Y. Rui and C.T. Sun. A Constitutive Model for AS4/PEEK Thermoplastic Composites Under Cyclic Loading. Purdue University Technical Report, CML 90-3, Submitted to NASA Langley Research Center, October 1990. 


\begin{tabular}{|c|c|c|c|c|c|c|c|c|c|c|c|c|c|c|c|c|c|c|c|}
\hline 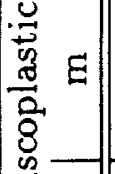 & $\mid \begin{array}{l}0 \\
\delta \\
0\end{array}$ & : & 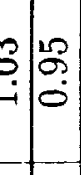 & $\left(\begin{array}{c}\infty \\
\infty \\
0\end{array}\right)$ & $\begin{array}{l}\sigma \\
\sigma\end{array}$ &  & 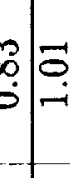 & $\begin{array}{l}\infty \\
i \\
i\end{array}$ & {$\left[\begin{array}{l}\uparrow \\
0 \\
0\end{array} \mid\right.$} & $\left|\begin{array}{l}2 \\
0 \\
0 \\
0\end{array}\right|$ & \begin{tabular}{l|l}
$R$ & $\infty$ \\
& 0 \\
\end{tabular} & 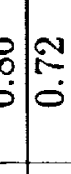 & $\mid \begin{array}{c}\infty \\
\infty \\
0\end{array}$ & 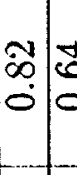 & $\begin{array}{l} \pm \\
\dot{0} \\
\end{array}$ & $\vdots \begin{array}{l}\infty \\
\infty \\
0 \\
0\end{array}$ & 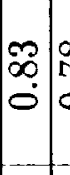 & & $\vdots$ \\
\hline 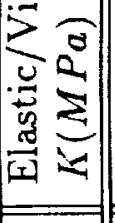 & 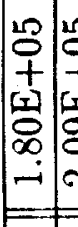 & 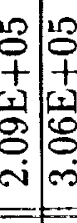 & 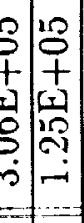 & 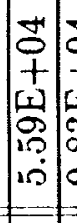 & 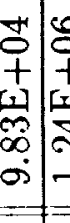 & 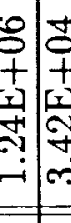 & 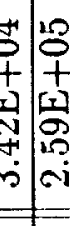 & 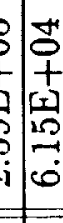 & 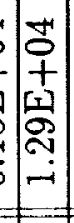 & 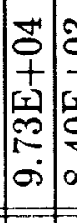 & 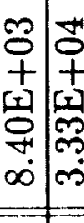 & 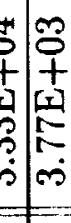 & $\mid \begin{array}{c}\infty \\
0 \\
+ \\
0 \\
20 \\
-\infty \\
\infty\end{array}$ &  & 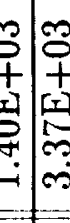 & 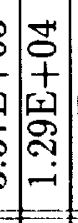 & 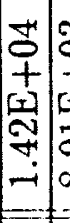 &  &  \\
\hline & $\mid$\begin{tabular}{l|l}
$\mid r$ \\
\end{tabular} & 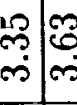 & \begin{tabular}{l|l}
0 & 0 \\
3 & +
\end{tabular} & $\mid \begin{array}{l}0 \\
0 \\
0\end{array}$ & \begin{tabular}{l|l}
$\dot{0}$ \\
$\dot{0}$ \\
$\sigma$
\end{tabular} & 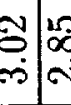 & 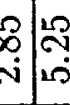 & : & $\mid \begin{array}{l}8 \\
0 \\
0\end{array}$ & $\left.\begin{array}{l}\sigma \\
0\end{array}\right)$ & \begin{tabular}{l}
$\infty$ \\
\multirow{7}{\infty}{} \\
$\dot{0}$
\end{tabular} & \begin{tabular}{l|l}
0 \\
$\vdots$ \\
0 \\
0
\end{tabular} & $\left|\begin{array}{c}\infty \\
⿱ 亠 乂 \\
0 \\
\vdots\end{array}\right|$ & \begin{tabular}{|l|l|} 
\\
$\infty$ \\
$\infty$ \\
$\dot{m}$ & 0 \\
\end{tabular} & 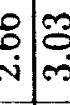 & $\mid \begin{array}{l}8 \\
0 \\
0\end{array}$ & $\left|\begin{array}{l|}\infty \\
\infty \\
10 \\
10\end{array}\right|$ & \begin{tabular}{l|l}
8 & 8 \\
&
\end{tabular} & ?ִ \\
\hline 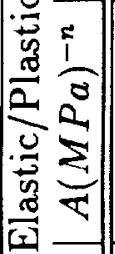 & 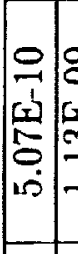 & 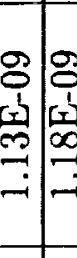 & 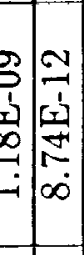 & 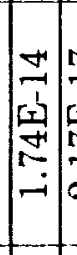 & 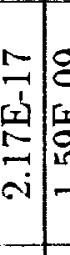 & 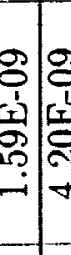 & 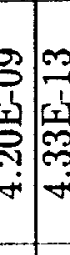 & 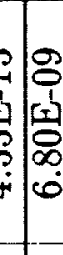 &  & 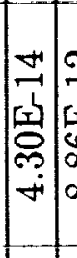 & 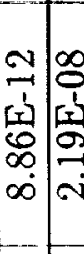 &  & 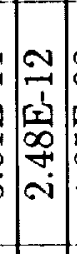 & 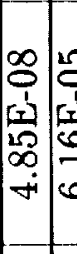 & 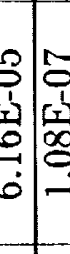 & 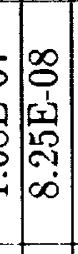 & $\begin{array}{l}= \\
= \\
5 \\
0 \\
0 \\
-5\end{array}$ & 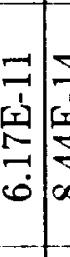 & 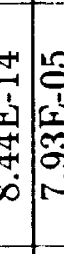 \\
\hline 8 & 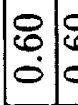 & \begin{tabular}{l|l}
0 & 0 \\
0 & 0 \\
0 & 0
\end{tabular} & \begin{tabular}{l|l}
$\dot{0}$ & $\stackrel{8}{0}$ \\
$\dot{0}$ & $\dot{0}$
\end{tabular} & $\begin{array}{l}8 \\
0 \\
0\end{array}$ & $\begin{array}{l}8 \\
\dot{0} \\
\end{array}$ & \begin{tabular}{l|c}
8 \\
$\dot{0}$
\end{tabular} & \begin{tabular}{l|l}
8 \\
$\stackrel{8}{\circ}$ & 8 \\
\end{tabular} & $\begin{array}{l}8 \\
\dot{0}\end{array}$ & $\begin{array}{l}8 \\
0 \\
\\
\end{array}$ & $\mid$\begin{tabular}{c|c}
8 \\
\hdashline \\
0 & 0 \\
0 & 0 \\
\end{tabular} & \begin{tabular}{l|l}
$\circ$ \\
m. \\
\end{tabular} & 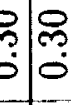 & $\mid \begin{array}{c}0 \\
0 \\
0\end{array}$ & |요 & $\stackrel{10}{0}$ & 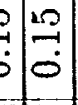 & $\mid$ & 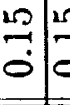 & $\begin{array}{c}0 \\
0 \\
0\end{array}$ \\
\hline$\stackrel{\Im}{\Xi}$ & 禺 & $\vec{\sigma}$ & \begin{tabular}{l|l|} 
\\
\end{tabular} & 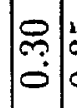 & ع & 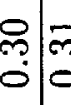 & $\stackrel{2}{\circ}$ & $\overbrace{}^{\circ}$ &  & مُ & ஸ் & مُ & 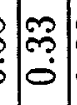 & 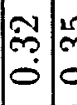 & مْ & $\begin{array}{l}\overrightarrow{0} \\
\vdots\end{array}$ & 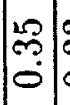 & 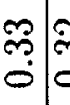 & $\stackrel{8}{c}$ \\
\hline 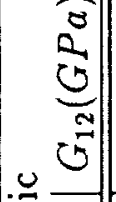 & {$\left[\begin{array}{l}3 \\
0 \\
10\end{array} \mid\right.$} & 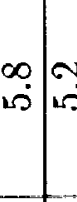 & \begin{tabular}{l|l}
$*$ \\
\hdashline \\
0
\end{tabular} & - & $\left.10\right|_{i} ^{*}$ & \begin{tabular}{l|l}
$*$ & $*$ \\
& $\infty$ \\
$i s$ & $\infty$
\end{tabular} & ז & $\int_{10}^{*}$ & $\vdots$\begin{tabular}{l}
$*$ \\
\hdashline \\
\hdashline 0
\end{tabular} & $\left|\begin{array}{c}* \\
20 \\
20\end{array}\right|$ & 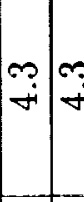 & סִ & $\overrightarrow{+i}$ & 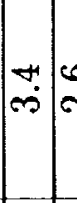 & 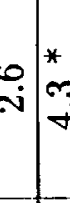 & 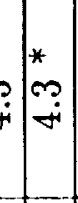 & $\left|\begin{array}{l}* \\
\sim \\
\sim \\
\infty \\
\infty\end{array}\right|$ & $\left.{ }^{*}{ }^{*}\right|_{\sigma} ^{*}$ & \\
\hline$\because \frac{0}{O}$ & $\infty$ & \begin{tabular}{l|l}
$\sim$ & $\infty$ \\
$\infty$ & $\infty$
\end{tabular} & \begin{tabular}{l|l}
$\infty$ & $\infty$ \\
$\infty$ & $\infty$ \\
\end{tabular} & $r$ & ס & $\begin{array}{lll}r & 0 \\
\infty & 0\end{array}$ & $\begin{array}{c}\infty \\
\infty \\
\infty\end{array}$ & \begin{tabular}{l|l}
$\circ$ & $\infty$ \\
$\dot{0}$ & $\infty$
\end{tabular} & $\begin{array}{l}0 \\
\dot{0} \\
\dot{R}\end{array}$ & | & $\therefore \sigma$ & Pי & $\stackrel{m}{r}$ & Nu & - & 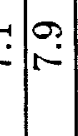 & Pי & 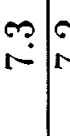 & \begin{tabular}{lll}
$*$ \\
\hdashline
\end{tabular} \\
\hline 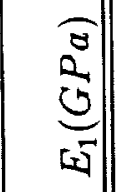 & 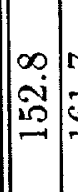 & \begin{tabular}{c|c}
$r$ \\
-0 \\
0
\end{tabular} & 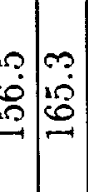 & 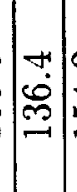 &  & 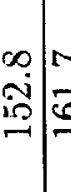 & 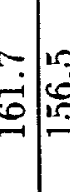 & \begin{tabular}{l|l}
0 \\
0 \\
0 \\
\hdashline & 18 \\
& 0
\end{tabular} & 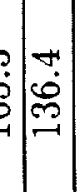 & $\left(\begin{array}{c}m \\
\stackrel{1}{2} \\
:\end{array}\right.$ & $\mid$\begin{tabular}{l|l}
0 & $\infty$ \\
$n$ & 0 \\
$n$ & $i n$
\end{tabular} & 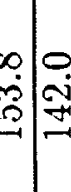 & 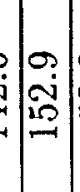 & 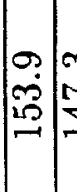 &  &  & $\mid \begin{array}{c}0 \\
\dot{j} \\
\dot{I}\end{array}$ & 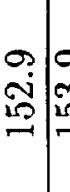 &  \\
\hline 0 & $\approx$ & $R:$ & $2: 18$ & $\stackrel{10}{2}$ & ఫ্ণী & 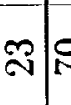 & $\stackrel{5}{2}$ & 2 & 5 & 㤩 & $\overparen{\curvearrowright}$ & 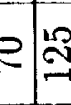 & 10 & $\stackrel{\mathscr{D}}{ \pm} \mid €$ & $\stackrel{8}{8}$ & Q & $\stackrel{2}{\Omega}$ & 욘 & \\
\hline 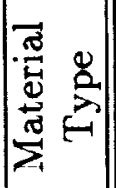 & & 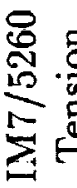 & & & & & 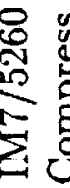 & 莕 & & & & $\sum^{\infty}$ & & & & $\sum_{\Sigma}^{\infty}$ & 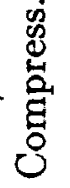 & & \\
\hline
\end{tabular}




\begin{tabular}{|c|c|c|c|c|c|c|}
\hline \multirow{2}{*}{$\begin{array}{c}\text { Material } \\
\text { Type }\end{array}$} & \multirow[b]{2}{*}{${ }^{\circ} \mathrm{C}$} & \multicolumn{3}{|c|}{ Elastic/Plastic } & \multicolumn{2}{|c|}{ Elastic/Viscoplastic } \\
\hline & & $a_{66}$ & $A(M P a)^{-n}$ & $n$ & $K(M P a)$ & $\mathrm{m}$ \\
\hline \multirow{6}{*}{$\begin{array}{c}\text { IM7/5260 } \\
\text { Tension }\end{array}$} & 23 & $\overline{0.60}$ & $2.91 \mathrm{E}-14$ & 5.33 & $2.27 \mathrm{~F}+05$ & 0.95 \\
\hline & 70 & 0.60 & $1.12 \mathrm{E}-13$ & 5.33 & $1.51 \mathrm{E}+05$ & 0.95 \\
\hline & 125 & 0.60 & $8.29 \mathrm{E}-13$ & 5.33 & $1.40 \mathrm{E}+05$ & 0.95 \\
\hline & 150 & 0.60 & $1.91 \mathrm{E}-12$ & 5.33 & $1.19 \mathrm{E}+05$ & 0.95 \\
\hline & 175 & 0.60 & $1.15 \mathrm{E}-11$ & 5.33 & $1.12 \mathrm{E}+05$ & 0.95 \\
\hline & 200 & 0.60 & $6.31 \mathrm{E}-11$ & 5.33 & $1.03 \mathrm{E}+05$ & 0.95 \\
\hline \multirow{6}{*}{$\begin{array}{l}\text { IM7/5260 } \\
\text { Compress. }\end{array}$} & 23 & 0.60 & $4.52 \mathrm{E}-12$ & 4.22 & $1.62 \mathrm{E}+05$ & 0.90 \\
\hline & 70 & 0.60 & $5.16 \mathrm{E}-12$ & 4.22 & $6.54 \mathrm{E}+04$ & 0.90 \\
\hline & 125 & 0.60 & $7.29 \mathrm{E}-11$ & 4.22 & $9.37 \mathrm{E}+04$ & 0.90 \\
\hline & 150 & 0.60 & $4.40 \mathrm{E}-11$ & 4.22 & $7.40 \mathrm{E}+04$ & 0.90 \\
\hline & 175 & 0.60 & $2.10 \mathrm{E}-09$ & 4.22 & 6.22 & 0.90 \\
\hline & 200 & 0.60 & $3.14 \mathrm{E}-08$ & 4.22 & $8.09 \mathrm{E}+04$ & 0.90 \\
\hline \multirow{6}{*}{$\begin{array}{c}\mathrm{IM} 7 / 8320 \\
\text { Tension }\end{array}$} & 23 & 0.30 & $1.94 \mathrm{E}-10$ & 4.66 & +03 & 0.81 \\
\hline & 70 & 0.30 & $1.82 \mathrm{E}-10$ & 4.66 & +04 & 0.81 \\
\hline & 125 & 0.30 & $6.25 \mathrm{E}-10$ & 4.66 & $8.69 \mathrm{E}+03$ & 0.81 \\
\hline & 150 & 0.30 & $6.28 \mathrm{E}-10$ & 4.66 & $7.43 \mathrm{E}+03$ & 0.81 \\
\hline & 175 & 0.30 & $3.92 \mathrm{E}-09$ & 4.66 & $2.51 \mathrm{E}+04$ & 0.81 \\
\hline & 200 & 0.30 & $1.52 \mathrm{E}-06$ & 4.66 & $6.78 \mathrm{E}+03$ & 0.81 \\
\hline \multirow{6}{*}{$\begin{array}{l}\text { IM7/8320 } \\
\text { Compress. }\end{array}$} & 23 & 0.15 & $8.63 \mathrm{E}-10$ & 4.35 & $8.13 E+03$ & 0.81 \\
\hline & 70 & 0.15 & $8.15 \mathrm{E}-10$ & 4.35 & $1.02 \mathrm{E}+04$ & 0.81 \\
\hline & 125 & 0.15 & $1.91 \mathrm{E}-09$ & 4.35 & $1.13 \mathrm{E}+04$ & 0.81 \\
\hline & 150 & 0.15 & $4.27 \mathrm{E}-09$ & 4.35 & $1.12 \mathrm{E}+04$ & 0.81 \\
\hline & 175 & 0.15 & $7.78 \mathrm{E}-09$ & 4.35 & $1.15 \mathrm{E}+04$ & 0.81 \\
\hline & 200 & 0.15 & $2.69 \mathrm{E}-06$ & 4.35 & $9.96 \mathrm{E}+03$ & 0.81 \\
\hline
\end{tabular}

Table 2: Material properties found from fixing the exponent in the power law expressions. 




Figure 1: Test specimen and fixture mounted in hydraulic test machine. 

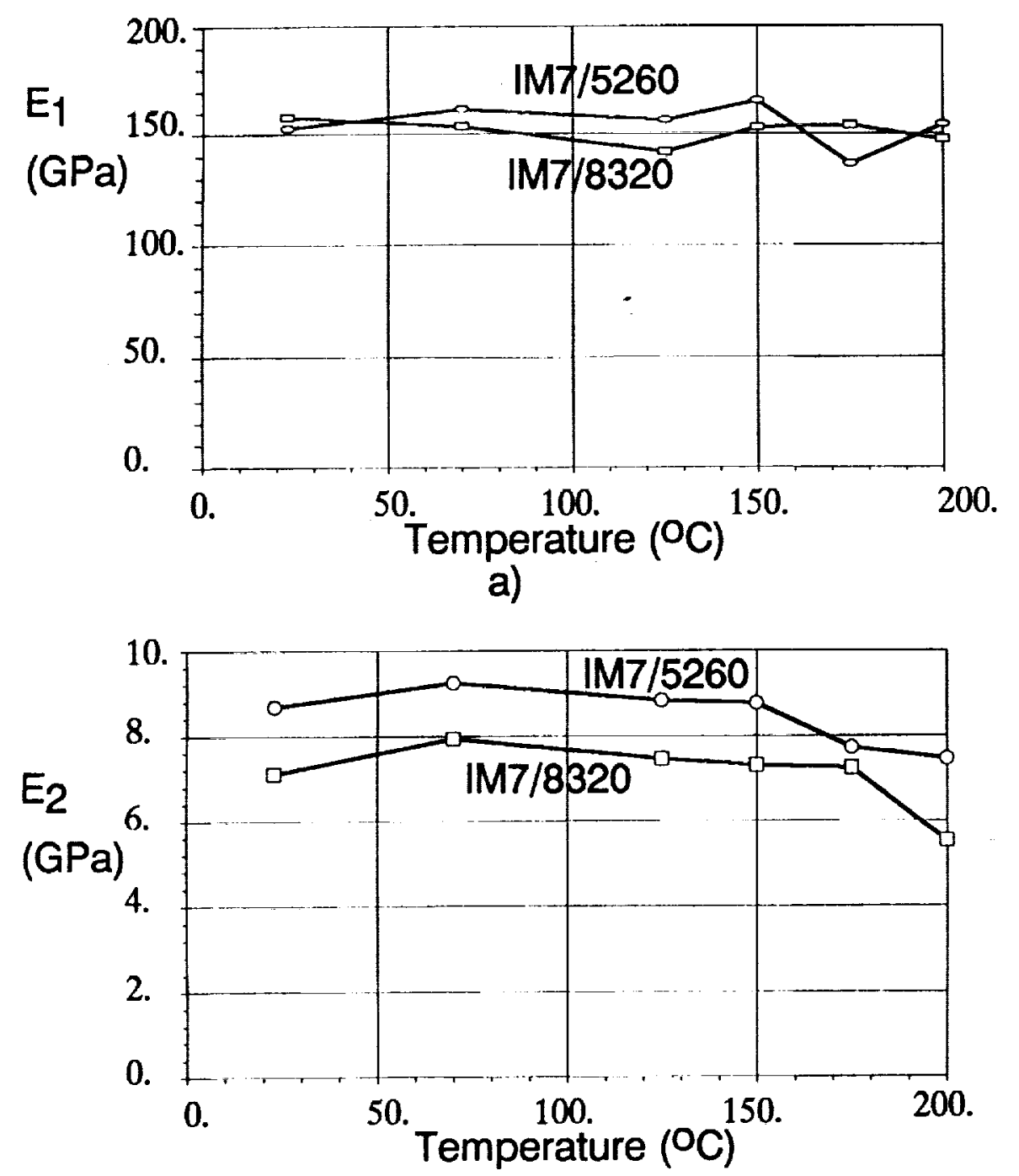

b)

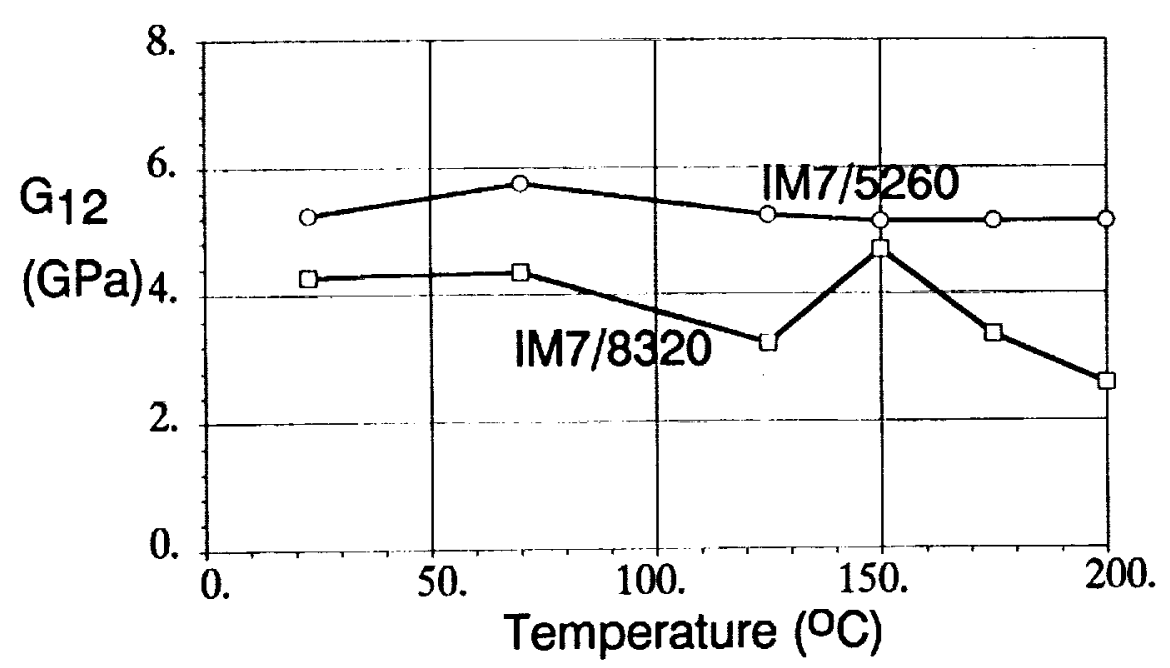

c)

Figure 2: Variation in measured elastic stiffness with temperature. a) Longitudinal Modulus, b) Transverse Modulus, c) Shear Modulus 


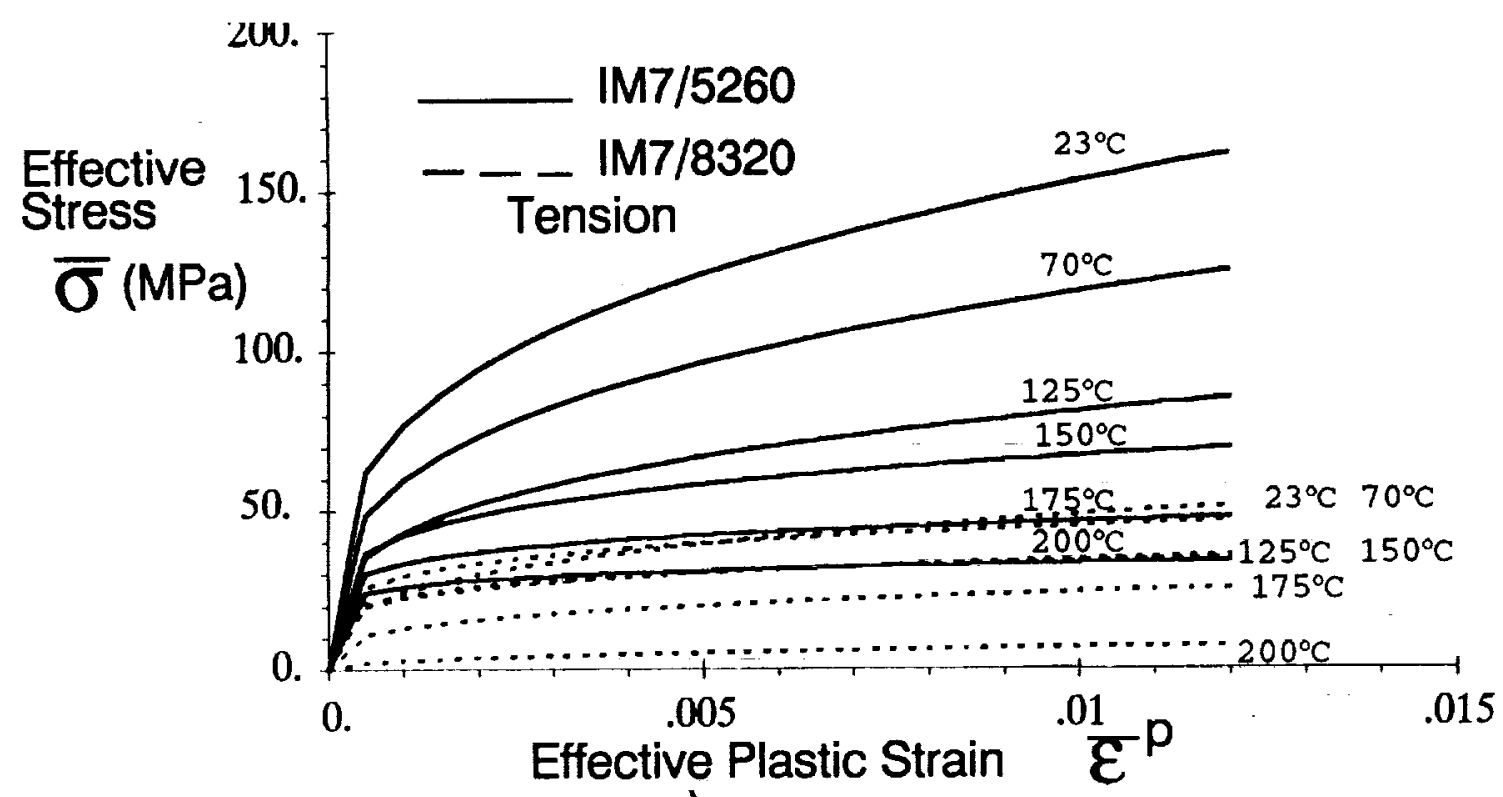

a)

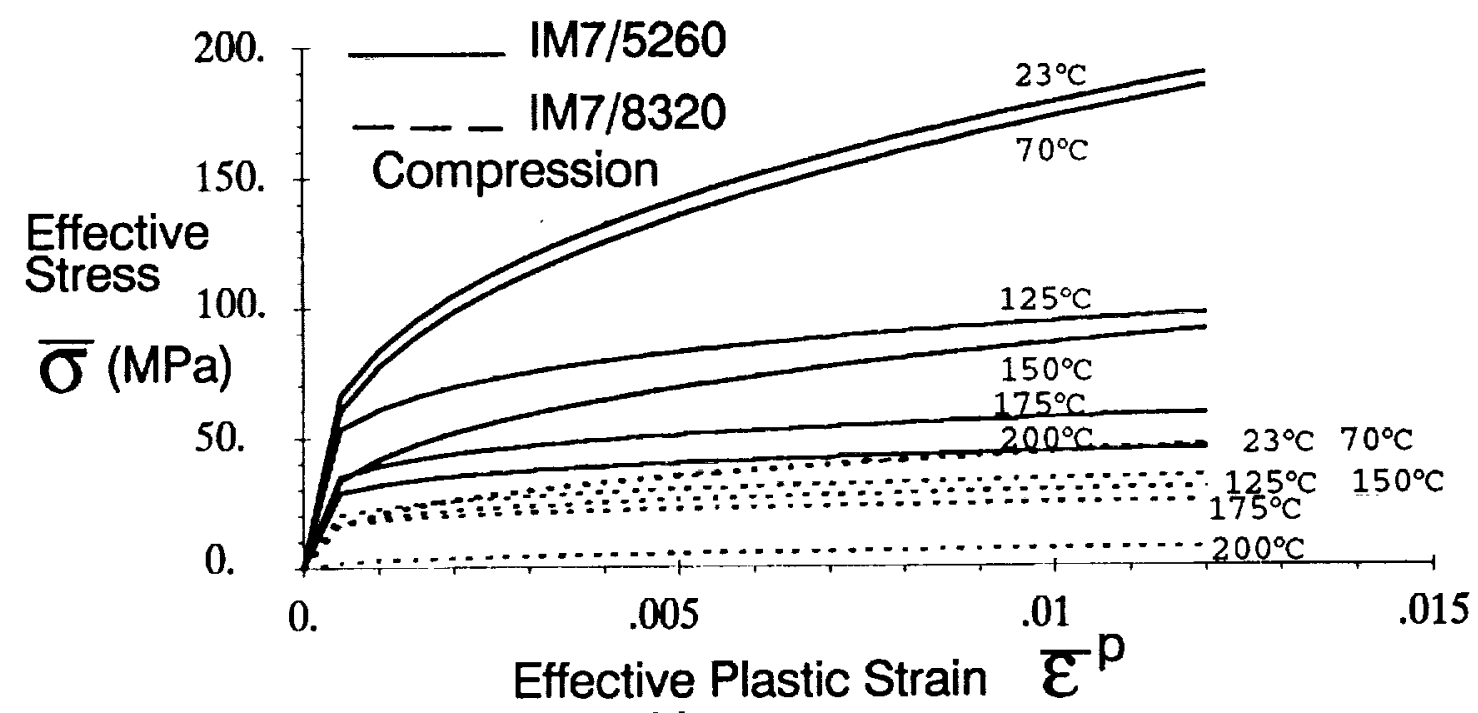

b)

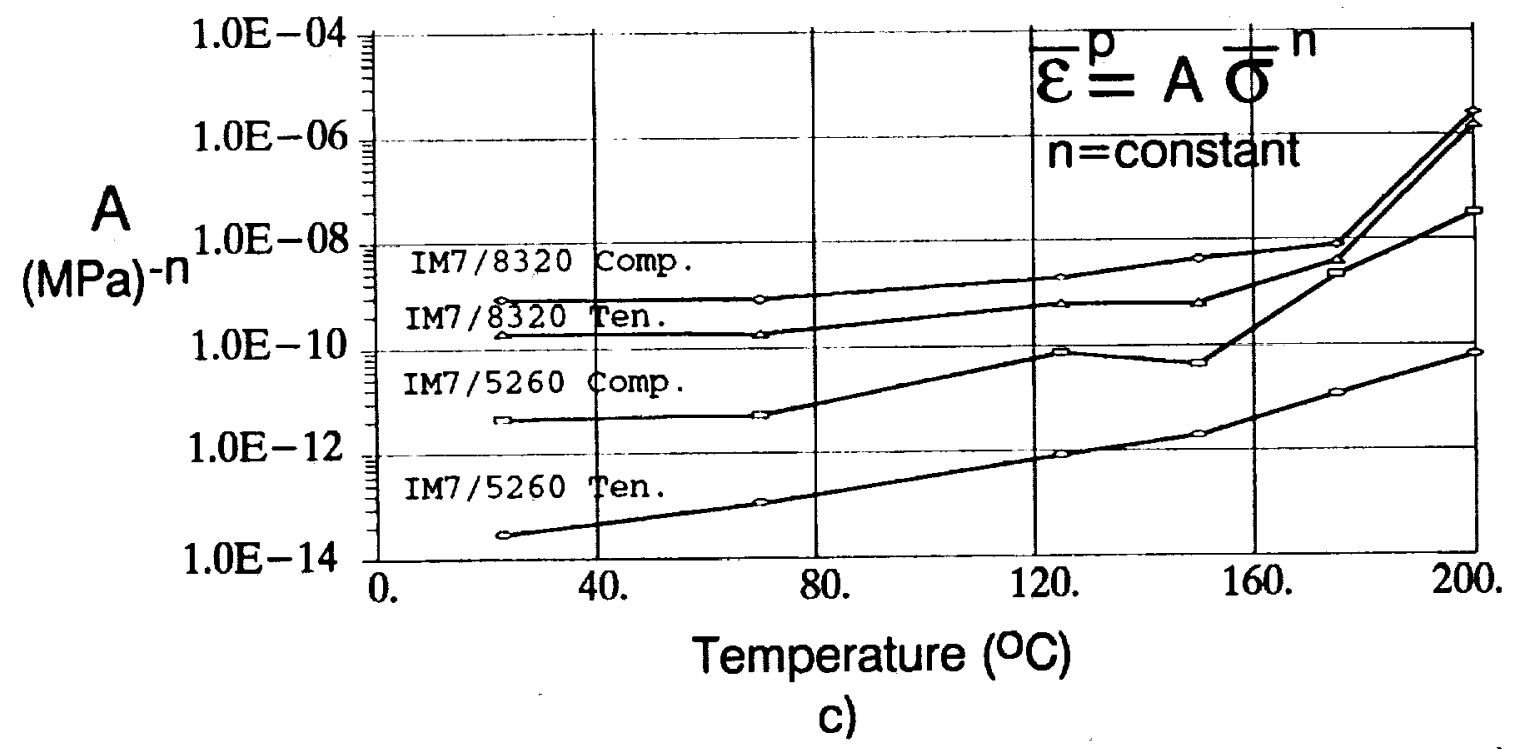

Figure 3: Quasistatic master curves for a) tension, b) compression loading. c) Variation in parameter $A$ for a constant value of $n$. 

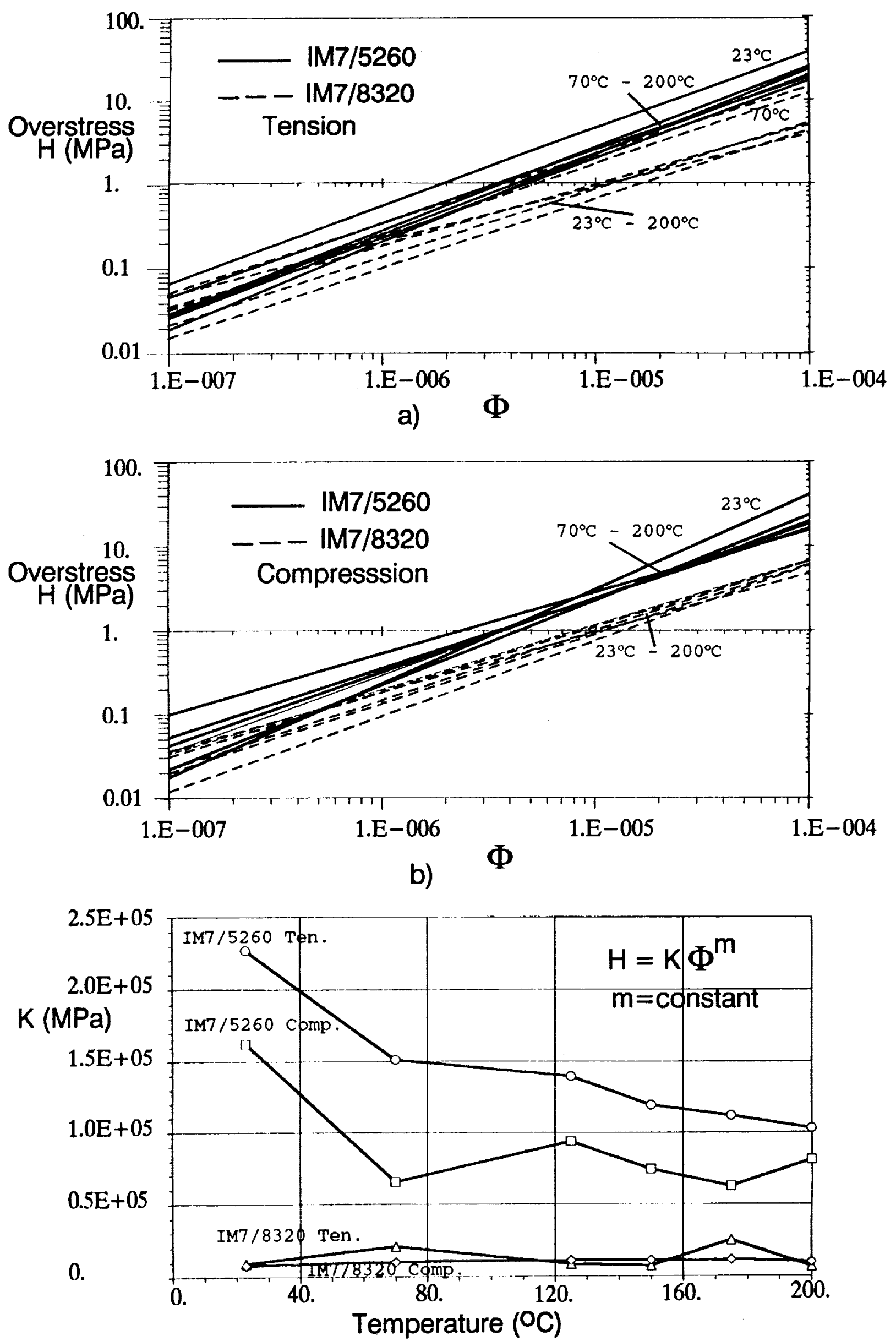

c)

Figure 4: Rate dependent master curves for a) tension, b) compression loading. c) Variation in parameter $\mathrm{K}$ for a constant value of $\mathrm{m}$. 

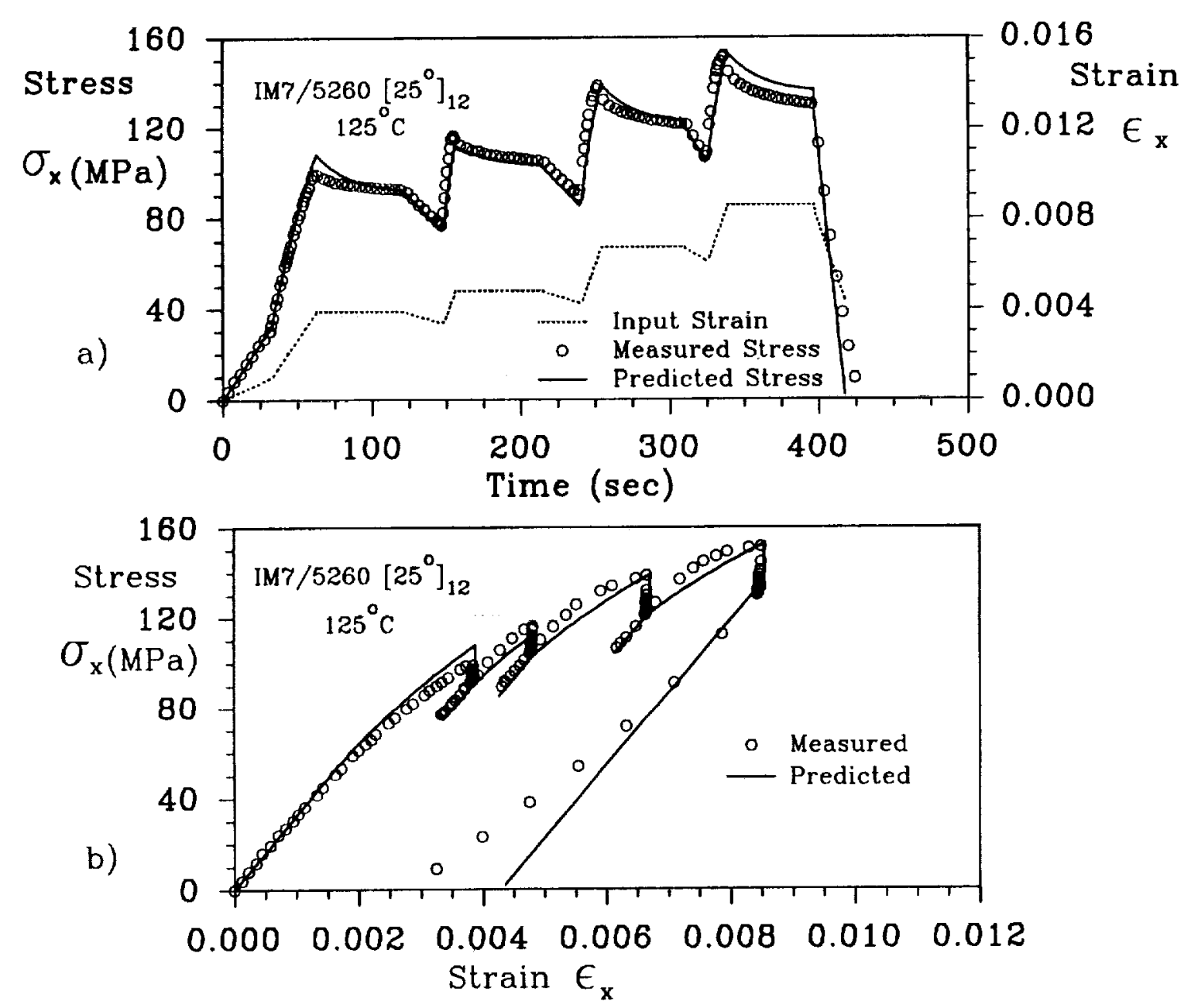

Figure 5: Comparison of test results and model predictions of a typical IM7/5260 $25^{\circ}$ off-axis tension specimen at $125^{\circ} \mathrm{C}$ under strain control. 



Figure 6: Comparison of test results and model predictions for a) $200^{\circ} \mathrm{C}$ tension, b) $175^{\circ} \mathrm{C}$ compression, off-axis specimens. 

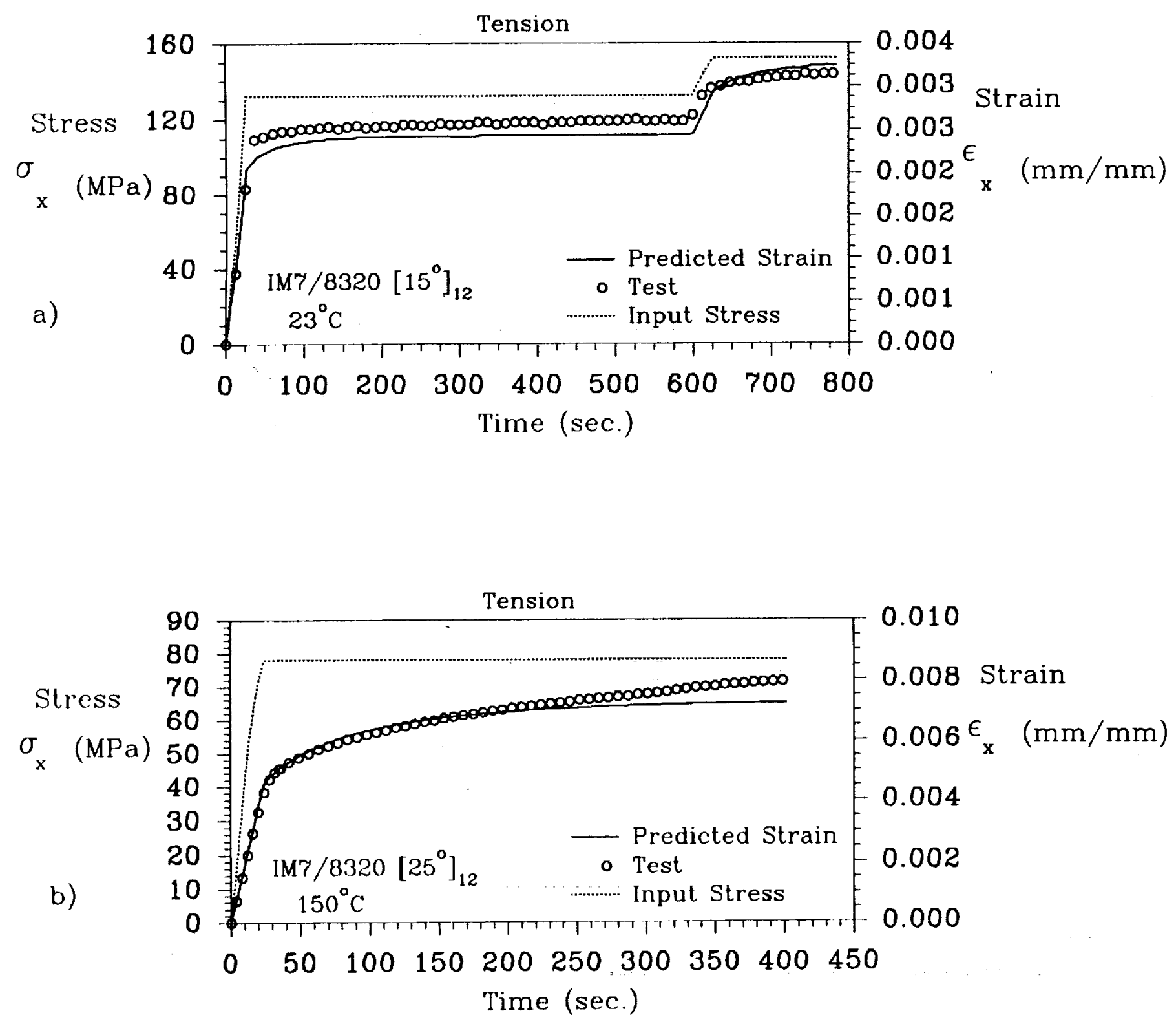

Figure 7: Comparison of test results and model predictions for a) $23^{\circ} \mathrm{C}$ tensile creep, b) $150^{\circ} \mathrm{C}$ tensile creep off-axis specimens. 


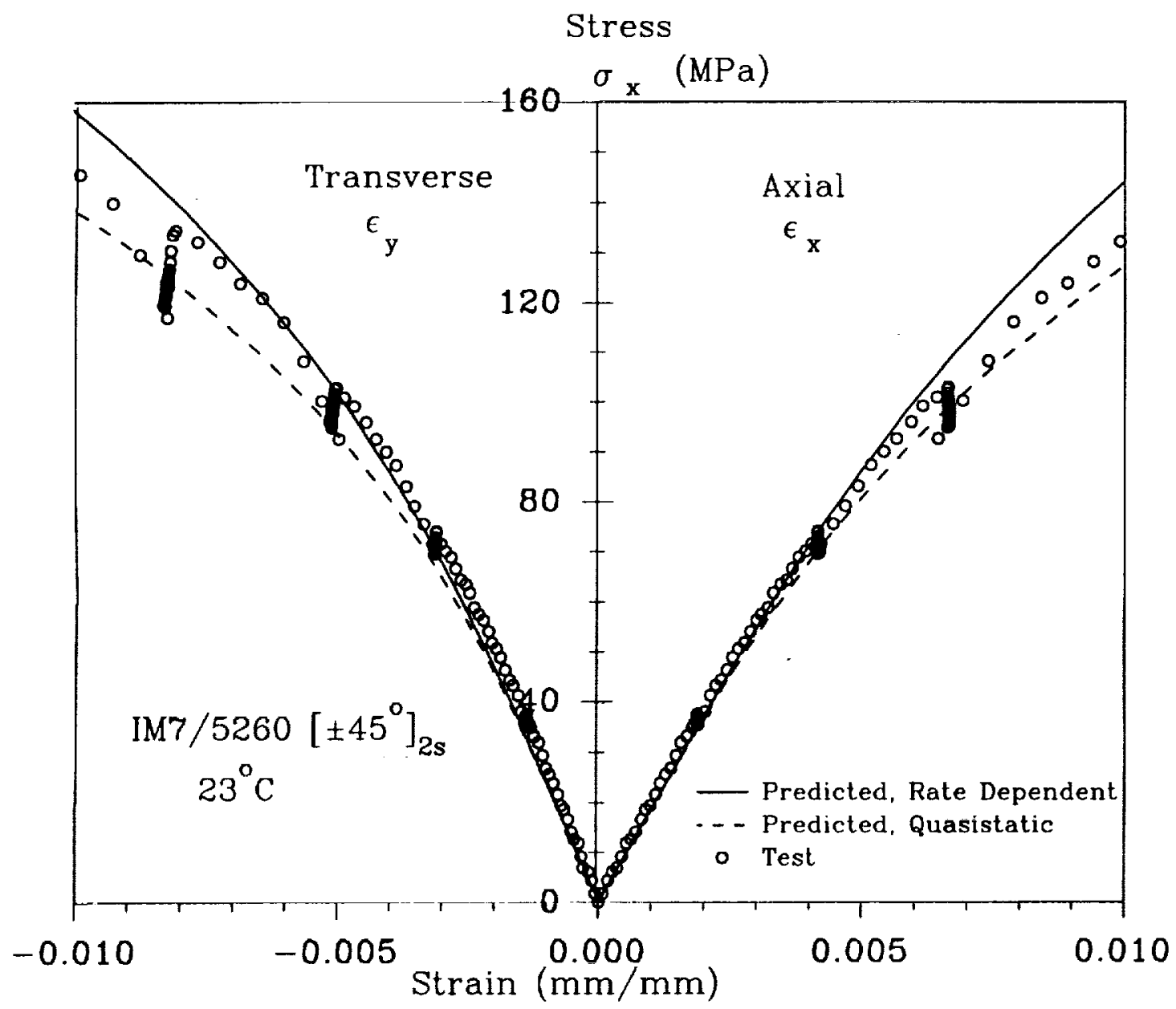

Figure 8: Comparison of test results and model predictions of a typical IM7/5260 $\left[ \pm 45^{\circ}\right]_{2 s}$ tension specimen at $23^{\circ} \mathrm{C}$ under strain control. 


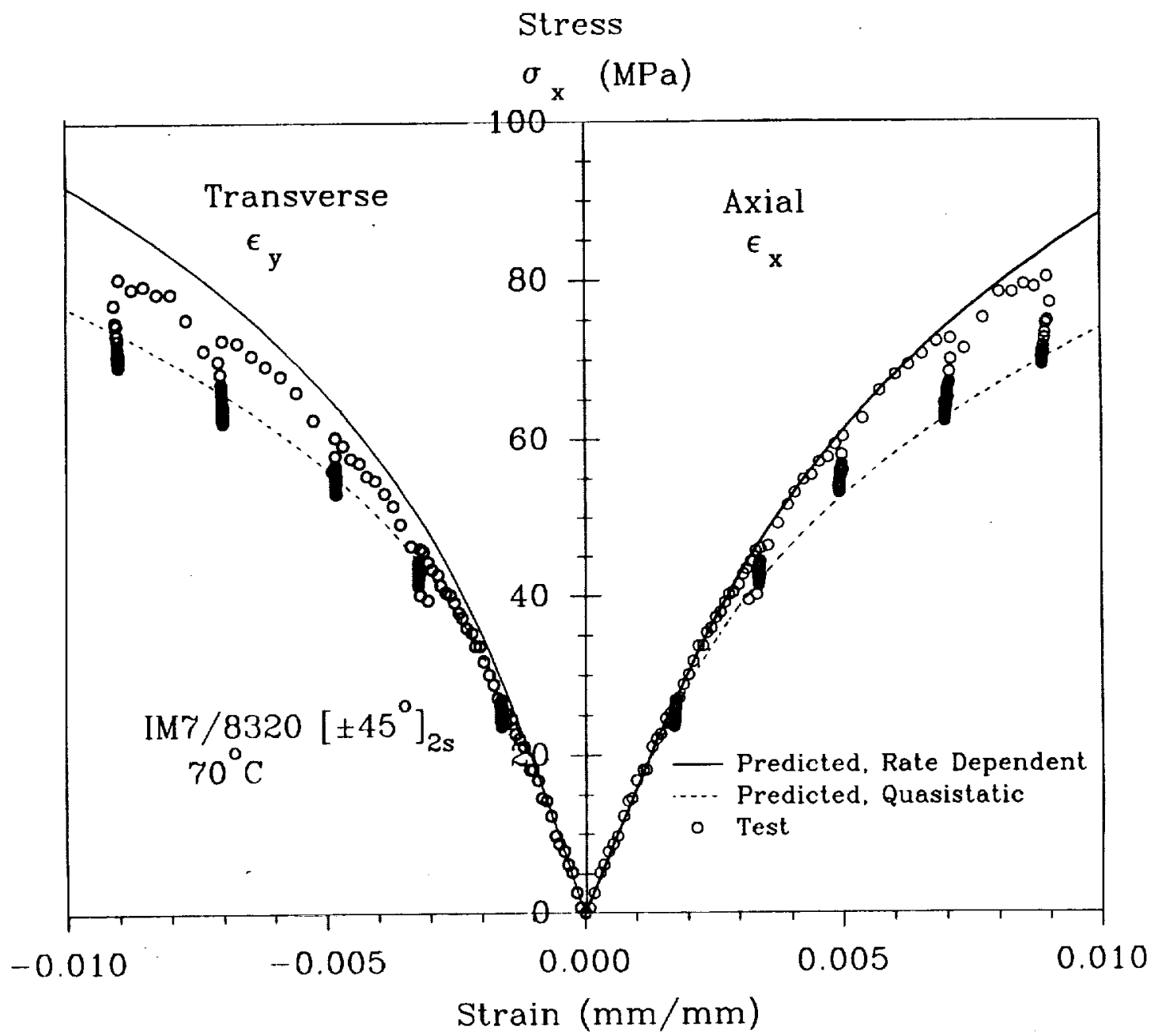

Figure 9: Comparison of test results and model predictions of a typical $\operatorname{IM} 7 / 8320\left[ \pm 45^{\circ}\right]_{2 s}$ tension specimen at $70^{\circ} \mathrm{C}$ under strain control. 




a)



Figurc 10: Effects of temperaturc on the predicted a) Stress relaxation at peak stress $=69 \mathrm{MPa}$, b) Creep of an off-axis specimen under tensile loading to $76 \mathrm{MPa}$. 


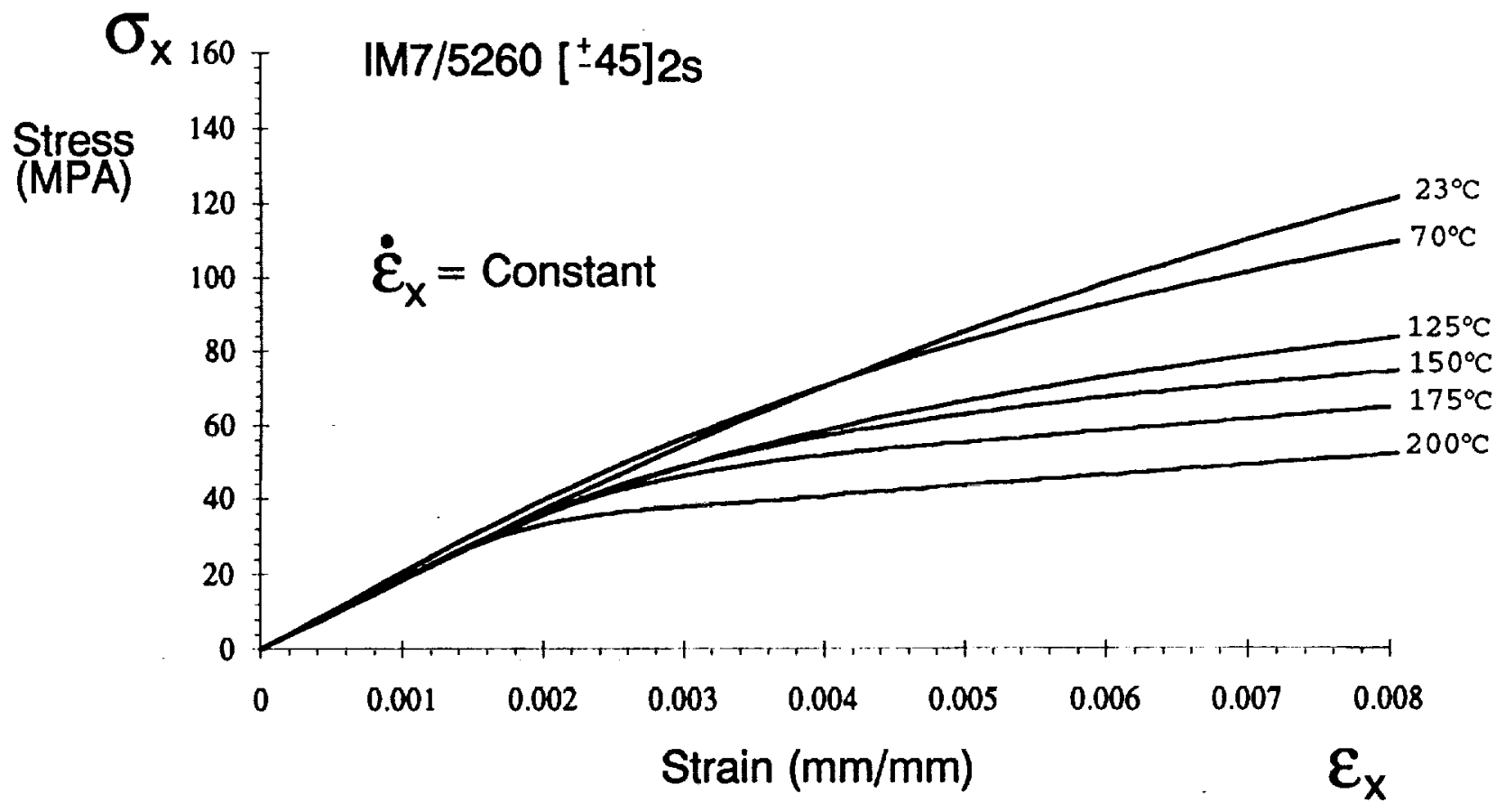

Figure 11: Effects of temperature on the predicted stress/strain behavior of a $\left[ \pm 45^{\circ}\right]_{2 s}$ specimen under tensile loading at a strain rate $=200 \frac{\mu \varepsilon}{\mathrm{sec} .}$. 
Public reporting burden for this collection of information is estimated to auerage I hour per response. including the time for reviewing instructions, searching existing data sources gathering and mantaining the data needed. and completing dnd reviawing the collection of information. Send comments regarding this burden estimate or any other aspect of this collection of information. including suggestions for reducing this burden. to Washington Headquarters Services. Directorate for Information Operations and Reports, 1215 Jefferson Mavis Highway, Suite 1204. Artington, VA 22202-4302. And to the Office of Management and Budget, Paperwork Reduction Project (0704-0188). Washington, DC 20503.

\begin{tabular}{|l|l|l|}
\hline 1. AGENCY USE ONLY (Leave blank) & $\begin{array}{l}\text { 2. REPORT DATE } \\
\text { October } 1991\end{array}$ & $\begin{array}{l}\text { 3. REPORT TYPE AND DATES COVERED } \\
\text { Technical Memorandum }\end{array}$ \\
\hline
\end{tabular}

4. TIITLE AND SUBTITLE

Effects of Elevated Temperature on the Viscoplastic Modeling of

Graphite/Polymeric Composites
5. FUNDING NUMBERS

$505-63-50-04$

\section{AUTHOR(S)}

Thomas S. Gates

7. PERFORMING ORGANIZATIOON NAME(S) AND ADDRESS(ES)

8. PERFORMING ORGANIZATION REPORT NUMBER

NASA Langley Research Center

Hampton, VA 23665-5225

NASA TM-104160

\section{SUPPLEMENTARY NOTES}

Presented at ASTM Symposium on "High Temperature and Environmental Effects on Polymeric Composites," San Diego, CA; October 15, 1991.

12a. DISTRIBUTION/AVALLBBILITY STATEMENT

Unclassitied - Unlimited

Subject Category - 24

\section{ABSTRACT (Maximum 200 words)}

In order to support the development of new materials required for the design of next generation commercial supersonic Iransports, a research program is underway at NASA to assess the long term durability of advanced polymer matrix composites (PMC's). In support of this program, recent work has provided test methods and an elastic/viscoplastic constitutive model which accounted for some aspects of rate-dependent tension and compression loading behavior of IM7/5260 and IM7/8320 materials throughout a range of useful temperatures. The research effort detailed in this paper is an extension of that work and had two main objectives. The first objective was to explore the effects of elevated temperature $\left(23^{\circ} \mathrm{C}\right.$ to $\left.200^{\circ} \mathrm{C}\right)$ on the constitutive model's material parameters. To achieve this goal, test data on the observed nonlinear, stress/strain behavior of $1 \mathrm{M7/5260}$ and $\mathrm{IM7/8320}$ composites under tension and compression loading were collected and correlated against temperature. These tests, conducted under isothermal conditions using variable strain rates, included such phenomena as stress relaxation and short term creep. From this data, trends in the parameters at elevated temperatures were developed, differences between the two material systems were outlined, and the significance of the parameters in terms of ductility and rate dependent behavior was established. The second major goal was the verification of the model by comparison of analytical predictions and test results for off-axis and angle-ply laminates. Correlation between lest and predicted behavior was performed for specimens of both material systems over a range of temperatures. Results indicated that the model provided reasonable predictions of material behavior in load or strain controlled tests. Periods of loading, unloading, stress relaxation and creep were accounted for. These types of studies should be useful for making comparisons on the effect of temperature between specific laminate types and material systems

\section{SUBJECT TERMS}

Polymer matrix composites; Viscoplastic; Tension; Compression; Elevated temperature; Stress relaxation; Creep

\section{NUMBER OF PAGES}

$$
30
$$

16. PRICE CODE

$\mathrm{AO3}$

\begin{tabular}{|l|l|}
\hline $\begin{array}{l}\text { 17. SECURITY CLASSIFICATION } \\
\text { OF REPORT }\end{array}$ & $\begin{array}{l}\text { 18. SECURITY CLASSIFICATION } \\
\text { OF THIS PAGE } \\
\text { Unclassilied }\end{array}$ \\
Unclassified \\
\hline
\end{tabular}
19. SECURITY CLASSIFICATION OF ABSTRACT

20. LIMITATION OF ABSTRACT 